\title{
VIOLENCIA DE GÉNERO APRENDIDA EN LA NARRATIVA DE LAS CANCIONES MODERNAS
}

\section{GENDER VIOLENCE LEARNED FROM CONTEMPORARY SONG LYRICS}

\section{ROSARIO DE FÂTIMA A'LMEA SUÁREZ ${ }^{1}$}

Recibido: 19 de junio de 2018 Aceptado: 22 de octubre de 2018

\footnotetext{
${ }^{1}$ Pontificia Universidad Católica del Ecuador, Quito, Ecuador, Rdalmea@puce.edu.ec
} 
iㅔlㅔ 240 


\section{VIOLENCIA DE GÉNERO APRENDIDA EN LA NARRATIVA DE LAS CANCIONES MODERNAS}

\section{GENDER VIOLENCE LEARNED FROM CONTEMPORARY SONG LYRICS}

Rosario De Fátima A'Imea Suárez

PALABRAS CLAVES: Violencia de género, canciones, narratología, relato amoroso, educación

KEYWORDS: Gender violence, songs, narratology, love story, education

\section{RESUMEN}

Este artículo académico se adjunta a la línea de análisis que desnaturaliza las prácticas contemporáneas de construcción de ciudadanías e identidades sociales a través de los medios de comunicación, que actúan a la par del currículo oficial, educando de manera indirecta bajo formas hegemónicas de género. El tema se centra en la narrativa de las letras de las canciones. El lector apoyará la ne- cesidad de lecturas críticas para los textos sociales de aparente entretenimiento. Para un diálogo teórico he recurrido a las propuestas post-estructuralistas y pos-críticas, aplicadas al material del mundo simbólico, como la lengua. Por ello, usaré presupuestos de la comunicación, de la semiótica, de la pragmática. De manera central, recurriré a la narratología, una técnica de lectura que parte de los elemen- 
tos diegéticos para interpretar. De ellos, me interesa la focalización pues devela la perspectiva ideológica, de poder y cómo se dan las relaciones internas.

\section{ABSTRACT}

This academic text follows the line of analysis that denatures the contemporary practices of citizenship construction and social identities through the media, which act alongside the official curriculum, indirectly educating below hegemonic forms of gender. The topic is thus focused on the content of song lyrics. The reader will support the need for critical readings for social texts which apparently serve entertainment. For a theoretical dialogue, I have turned to post-structuralist and post-critical proposals, applied to the material of the symbolic world, such as language. I will therefore use assumptions from communication, semiotics, and pragmatics. As a central element, I will resort to narratology, a reading technique that evolves out of the diegetic elements to be interpreted; of these, I am interested in focalization, because it reveals the perspectives of ideology and power, and how internal relations occur.

\section{INTRODUCCIÓN}

En nuestra realidad, tanto oriental como occidental, los medios de información han tomado un papel que sobrepasa el entretenimiento. Sus mensajes acceden a los sentidos de la lengua y, por lo tanto, reactualizan el mundo simbólico vigente como cualquier texto o discurso social. En el ámbito educativo, se los ha invalidado como generadores de conocimientos y aprendizajes. Sin embargo, a la par que el currículo oficial, estos actúan y trabajan en lo denominado currículo oculto, como lo proponen des- de los estudios culturales y del discurso, ya que estos son parte del sistema social.

Detengámonos en las canciones, las cuales desde el nacimiento de las culturas han acompañado al ser humano y le han servido para reflejar sus estados emotivos, ya sea ante lo extraordinario o lo inexplicable de la naturaleza y su estar en el mundo como agrupación (canto mítico-religioso); luego, para ensalzar a sus héroes (canto épico); y, luego, expresar su sentir particular (canto lírico). Hoy ese tipo intimista se ha populariza- 
do con las canciones, donde se actualiza la lengua (Ricœur, 2001). Por lo tanto, son textos fijados en el tiempo-espacio (Cortés y Camacho, 1989), pues imbrican una letra y una melodía con una puesta en escena, lo que conlleva al uso de otros lenguajes. De esta forma, aparecen estructuradas en los medios de información, donde se ponderan dos canales de estesis: auditivo y visual.

Si nos enfocamos en el mensaje verbal, entendemos que la letra es pensada por alguien (creador /a), quien, a partir de una necesidad, elige y ordena (locution) lo que será el sentido proposicional (Austin, 1962; Ricœur, 2001). Además, se otorga una fuerza enunciativa (ilocution) para ser comprendida y pro- ducir un efecto (perlocution). Vista así, la letra de las canciones dice y también logra que se haga algo (carácter performativo).

¿Quiénes son los que se identifican más con estos textos? Los y las jóvenes que se sienten reflejados uso de su sociolecto-, ya sea por la letra, por el ritmo, por el vestuario, por las imágenes, por los artistas, por una empatía con un marco personal -la relación amorosa- o por creer que representan su cultura, diferente a la adultocéntrica (Jurjo Torres Santomé en Tomaz Tadeu da Silva, 1995), y hacen que vean en estos discursos su bandera, pues los grupos optan por estas formas expresivas como manifiesto.

\section{OBJETIVOS}

Las interrogantes que dilucidaré en este trabajo son: ¿las canciones de moda, por ser parte del uso de la lengua, tendrán una estructura discursiva determinada? ¿En los mensajes expuestos en las canciones de moda se pueden rastrear aprendizajes de género? ¿Ellas pueden ser consideradas como dispositivos que coadyuvan al aprendizaje de los roles de género? ¿Ellas pueden ser un canal por donde la violencia de género se filtra?

Las canciones de moda, como parte del discurso social, sirven como dispositivo del sistema vigente porque reflejan en sus letras (contenido) el mundo simbólico socializado como hegemónico, lo cual cimenta aprendizajes validados, que son interiorizados de manera directa y rápida, porque recurren a lo emotivo y a la repetición. Esta intencionalidad está velada, por lo que me propongo interpretar el proceso de funcionamiento de estos mensajes, donde planteo que, para su efecto, recurren a una macroestructura, que es de fácil asimilación -aprendizaje- y 
que no es nueva, sino que ha sido una constante desde hace muchas generaciones. Por ello, es rastreable su relación con el poder, la historia, la ideología y las desigualdades sociales -violencia de género- (Wodak y Meyer, 2002), donde no se admite la diversidad a lo establecido.
Bajo estos objetivos, dejo en sus manos el presente artículo, donde resalto la investigación realizada, que, además de los expuestos, argumenta por una relectura y desnaturalización de los mensajes mediáticos que a diario recibimos y pido del lector su adición a este cuestionamiento.

\section{MATERIALES, METODOLOGÍA Y MARCO TEÓRICO}

Para la consecución de esta investigación requerí de dos momentos: uno empírico y otro interpretativo-bibliográfico. En el primero, debí obtener el corpus. Para ello, escogí un grupo focal para que me ayudase con el listado de las canciones preferidas en el lapso de noviembre de 2006 a marzo de 2007, cuando ubiqué el estudio de campo. Aquel pertenecía al propedéutico (dos cursos de 37 personas cada uno) de una universidad privada de la ciudad de Quito. Participó por dos razones: por la apertura y facilidad para trabajar, brindada por la institución -a la que agradezco-, y, por tratarse de jóvenes heterogéneos, pues venían de diferentes espacios educativos, económicos y geográficos del Ecuador.

El grupo estaba conformado por 74 personas, entre hombres y mujeres, con un número homogéneo. Lo impor- tante fue la consolidación de la lista de las canciones en boga en un tiempo y espacio determinados, y aceptado por ellos como parte de sus afectos. De igual manera, procedí en la investigación anterior, donde un grupo similar pero de edad menor me ayudó (14-15, colegio). Esta vez, preferí una edad mayor (17-19, universidad), pues, por su capacidad evolutiva y cognitiva, estaban en el proceso final de consolidación de esquemas sociales y, por lo tanto, se podía crear conciencia con un mejor cuestionamiento.

Como fue una recolección de datos recurrí a un método cuantitativo -estadístico-. El instrumento empleado fue la encuesta y la tomé a finales de febrero del 2007. La pregunta solicitaba diez títulos de las canciones preferidas -y sus cantantes- en ese lapso. Tenían dos exigencias: ser de moda -no importaba el ritmo- y estar la lengua española. Ob- 
tuve lo deseado con gran aceptación y participación del grupo. Con ese corpus, procedí a clasificar las diez más populares según el puntaje obtenido.

Luego, con el listado completo, revisé si todas ellas poseían una letra o lírica. Después de este filtro determiné el corpus, pues todas ellas cumplían con este requisito. Entonces, me dediqué a la lectura y comprensión del mensaje, al cual pude considerar como producto de la actualización -acontecimiento y sentido- de la lengua (Ricœur, 2001). Asimismo, reconocí que todas ellas manejaban una constante en su estructura, lo que me llevó a optar por los presupuestos de Teun van Dijk (1980; 2007), así, deduje que la macro-estructura empleada era única.

De la comprensión primaria extraje una conjetura probable (Ricœur, 2001): las canciones cuentan una historia, por lo tanto, recurren a la estructura del relato. Para la interpretación, la técnica idónea era la narratología (Sullà, 1996; Corrales, 2000), propuesta de la crítica literaria, que metadiscursivamente se ha adaptado al análisis crítico del discurso, donde se saca una estructura recurrente, a partir de la relación de sus elementos: fábula (acontecimientos en orden cronológico), historia, (cómo se presentan los acontecimientos, cómo se cuenta), el narrador (quien cuenta los acontecimientos), los personajes (entes de fic- ción que actúan en la historia, cada uno con su comportamiento o ethos como aplica Maingueneau, 1996), las voces (uso de textos o discursos intercalados, hipotextos), la focalización (perspectiva o plano desde donde se presentan los acontecimientos o a través de los ojos - o sentidos- que dan relevancia lo narrado, donde se plasma lo psicológico, ideológico y espacio-temporal), el punto de vista (cosmovisión o manera de ver el mundo proyectado en un texto o en un enunciado o discurso).

Para este análisis narratológico, comparé cada elemento y sus constantes o diferencias, mediante una matriz, y a partir de este análisis pude aplicar la conjetura que guía esta investigación.

En el último punto, tomé los resultados obtenidos y los ordené según su mayor relación con lo ideológico y social. Comencé por la focalización, luego, el narrador y, al final, el punto de vista, sin deslindarme del tiempo-espacio. Este último me indicó que se trataba de una determinada escenografía (Maingueneau, 1996): la relación amorosa, donde era factible analizar los marcos (Calsamiglia y Tusón, 2001). En este caso, deduje la ubicación de la frontera temporal de ese momento vivencial: el inicio o el final de la relación amorosa.

Siguiendo, mi conjetura lo propio era proceder con la interpretación. Con los planteamientos del análisis del 
discurso, me centré en los avances teóricos sobre la violencia de género que, bajo la visión de las teorías críticas y el análisis crítico, proponen que todo enunciado comunicativo dentro de la sociedad está cargado de una intención, es decir, encierra un sesgo socio-político (Wodak et al., 2002). A su vez, en esta misma línea está el análisis de género, cuyo interés se centra en la utilización lingüística de la naturalización de la función de la mujer, sus roles, sus relaciones afectivas y de poder-casi inexistente-. Asimismo, tomé aportes de M. Foucault (1976; 1990; 2000), en especial, su planteamiento del dispositivo de la sexualidad, que domina al sujeto (entendido como el que está sujeto / a). Él lo llama el biopoder y usa dos técnicas para esta consecución: la primera, anatomopolítica, enfocada en los comportamientos del individuo (vigilancia, control, intensificación del rendimiento, multiplicación de capacidades, emplazamiento, utilidad de su cuerpo), para tener volun- tades dóciles y fragmentadas: sujetos obedientes, disciplinados. Y la segunda, biopolítica, dirigida al grupo, a la población, a la especie. Se usa a los procesos y leyes biológicas para convertirlas en modos de dominación y control. A través de los discursos, se construyen conocimientos y representaciones que trabajan en pro de las clases dominantes y vigilan su normal consecución.

Esta fue la metodología empleada para cada momento de la investigación. Cada resultado obtenido sirvió para continuar con el paso siguiente. El camino presentado puede aplicarse en otros corpus como los videos musicales -como lo realicé en el periodo 19971998-, las novelas, los cuentos infantiles, la ópera, la publicidad, los textos didácticos, cómics, la letra de los himnos nacionales y particulares, de colegios, equipos y otros, el discurso del chiste o del insulto, las películas que toman como hipotexto los cuentos de hadas o las historietas de héroes, etc.

\section{RESULTADOS}

Como expliqué en la metodología, mi investigación tuvo dos momentos. En el primero, obtuve el corpus de las canciones de mayor preferencia en lengua española y en el periodo escogi- do. Así, de las veinticuatro presentadas, solo diez llegaron a tener un rango de elección entre el $81 \%$ y $92 \%$, por consiguiente, fueron las empleadas para validar la conjetura propuesta. 


\section{Cuadro n. ${ }^{0} 1$}

\section{Lista de canciones proporcionadas}

\begin{tabular}{|l|l|l|c|c|}
\hline 1 & Labios compartidos & Maná & 68 & $92 \%$ \\
\hline 2 & Maldita bruja & Chris Rivera & 66 & $89 \%$ \\
\hline 3 & Tu recuerdo & Ricky Martin & 65 & $88 \%$ \\
\hline 4 & Bendita tu luz & Ricky Martin & 66 & $89 \%$ \\
\hline 5 & Ser o parecer & RBD & 65 & $88 \%$ \\
\hline 6 & Limón y sal & Julieta Venegas & 63 & $85 \%$ \\
\hline 7 & Baila, mi vida & Fausto Miño & 63 & $85 \%$ \\
\hline 8 & Frente a frente & J. Fndo. Velasco y G. Mejía & 60 & $81 \%$ \\
\hline 9 & Mentirosa & Elefante & 68 & $92 \%$ \\
\hline 10 & Noviembre sin ti & Reik & 67 & $91 \%$ \\
\hline
\end{tabular}

Fuente: Autor

Nota: Corpus con puntaje alto. La lista fue de 24 canciones y correspondieron al periodo 2006-2007.

En el segundo momento, analicé cada una de las letras y comprobé que todas (100\%), empleaban el relato como macroestructura. Esta presentaba a un "yo" que conocía a un "tú", se enamoraba y contaba esta experiencia amorosa, es decir, la escenografía era única. Por lo tanto, las letras de las canciones sí empleaban una estructura discursiva para su creación textual. Esta es muy conocida, pues es la primera aprendida en el acto de socialización y, por lo tanto, es reconocible para el cerebro (Van Dijk, 2000), porque es así como se aprende a "construir" (macrorreglas) la información para guardarla en la memoria a largo plazo.
Con este resultado, pude aplicar la técnica de la narratología; entonces, localicé los ocho elementos que había especificado en el acápite anterior. Sin embargo, uno de ellos se convirtió en el más relevante y el cual determinaba a los otros: la focalización. Así, en el corpus, el $80 \%$ fue masculina y el $20 \%$, femenina, es decir, hubo coincidencias entre el sujeto del enunciado (el personaje-narrador protagonista del monólogo) y el de la enunciación (el cantante o grupo que hace de garante), lo que se conoce como narrador homodiegético.

En cuanto a la historia narrada desde ellos concluí que diferían en cuanto a la frontera temporal, el $87,5 \%$, se 
ubicaba al final de la relación amorosa, mientras el 13,5\%, lo hacía al inicio.

Los de mayor porcentaje empleaban un narrador en primera persona con el recurso del monólogo. En la fábula se representaban como un "yo" masculino que conocía a un "tú" femenino. Luego, se convertían en pareja y ella lo dejaba porque encontraba a otro o estaba con otros al mismo tiempo (lo traicionaba). Él, que había sido fiel, se sumía en el dolor, el alcohol, la negación, porque su amor sincero había sido vituperado.

Este momento de desesperación (lugar y tiempo de enunciación) era el detonante para contar la historia a un público empático. Los acontecimientos eran evocados y a partir de ese recuerdo se creaban las circunstancias, los tiempos y espacios. Asimismo, al configurar al otro personaje, se demostraron dos maneras: una negativa e insultante $(85,7 \%)$ como en "Labios compartidos", "Maldita bruja,, "Tu recuerdo," "Baila, mi vida", "Frente a frente" $y$ "Mentirosa". En la otra, el "yo masculino" prefería describir su estado de ánimo, su abandono y su tragedia $(14,2 \%)$, como en "Noviembre sin ti" $y$ "Tu recuerdo".

Cuando la frontera temporal se situaba en el inicio de la relación amorosa, el "yo" masculino hacía una configuración de la mujer imaginaria y la metamorfoseaba con un "ángel", es decir, la idealizaba hiperbólicamente. En esa escenografía del enamoramiento, se empleó imágenes etéreas tanto para el cuerpo como para el comportamiento. En este último, se presentaba ambivalencias pues, ella era quien lo desdeñaba pero, a la vez, lo tentaba con sus cualidades divinizadas (hermosas tanto del cuerpo como del alma). Se representaba una relación "yo-tú", en la cual él era el amado, subyugado ante esa hermosura: su rol era el del vencido, igual que un esclavo ante su Ama. Este tema lo tenemos en "Bendita tu luz".

Inferí que la focalización variaba con respecto a la frontera temporal de la escenografía amorosa, pues esta incidía en la percepción de la representación femenina y la manera cómo se expresaban de sí mismos y sobre ella. en ambas narrativas, la voz femenina no se dejaba oír, se la representó como un personaje plano y como un "actante" que cumplía de objeto, pues era deseado o repudiado por el sujeto narrador.

En cuanto al grupo con focalización femenina, solo se seleccionaron dos canciones, lo que corresponde al 20\%. Sin embargo, cada una ejemplifica dos fronteras temporales distintas. En un caso, la narradora y sujeto de la enunciación se ubica en un tiempo previo a la experiencia amorosa correspondida, pues cuenta sus intentos por conseguir a su amor platónico (50\%), mientras la otra lo hace desde el proceso mismo, lo 
que nos presenta los acontecimientos in medias res (50\%). Estos, en ambos casos, son evocados pues entramos en el plano de la memoria y de allí se ordena la fábula. Los detalles previstos al tiempo narrado son explícitos en la primera voz, mas no se da así en la otra, pues prefiere narrar ese presente y un posible futuro. Desde esa rememoración se inscriben a sí mismas y a sus sujetos amados.

Cuando lo hace la voz femenina que desea conseguir ser "vista", esta se representa como una joven enamorada, casi "loca", soñadora, llena de ilusiones por conseguir ese propósito. Este es el cual la mantiene viva y, a la vez, le llena de esperanza pero le hace sufrir. Su carácter luchador es lo que la hará diferente. Todos estos atributos contradictorios solo tienen un fin: tener el amor de él, que incluso es comparado con una "luz" que la ilumina. Según su percepción se nos presenta él: un joven atractivo, decidido y asediado por otras mujeres, que cuidan de su apariencia y que ellas debe descubrir cuál es su preferida para mimetizar.

Cuando lo hace la voz femenina que se sitúa en la mitad de su relación amorosa, tenemos una representación alternativa de ambos. Para ella, está el amor incondicional, la espera, la sumisión, la aceptación del otro tal como es, el no imaginar o intentar cambiarlo, aunque, a veces, no aguante sus cambios de humor, el que se desaparezca sin decir nada, que no sea "romántico" o, incluso, si no "está seguro de lo que siente", ella está tan enamorada que lo perdona, porque solo su compañía le hace "volver a empezar" o una mirada suya le hace ser "feliz". En esta conciencia, la figura de él se la representa como un hombre independiente que no se sujeta a compromisos, su carácter es fuerte $y$, muchas veces, irascible, no es cariñoso. No se alude a su físico sino solo a "su forma de ser".

Con estos resultados deduje que las letras de las canciones emplean una macroestructura narrativa, y que hay una elección de una escenografía: la relación amorosa, donde las relevancias de qué contar estaban determinadas por la focalización, que podía ser masculina o femenina. A través de esta se configuraban unos y otros, además se mostraban los afectos y determinadas funciones para cada uno, las cuales reflejaban duplican los roles y aprendizajes sociales dados a cada uno de los dos géneros existentes, ya que estos personajes de ficción hacían una mímesis del mundo real. Asimismo, comprobé que la focalización masculina plasmada en las letras de las canciones era la más aceptada por el grupo de jóvenes. Por lo tanto, ellos no discriminaban esta diferencia, lo que me lleva a inferir que está naturalizado este relato en su competencia textual y discursiva. 


\section{DISCUSIÓN}

En nuestra realidad occidental, el sistema social ha sido construido a partir de la creencia de la existencia de una sola verdad (metafísica), fundamentada en la razón (llustración, positivismo), lo que ha procurado una bipartición en todos los campos. Jacques Derrida lo llamó el logocentrismo (1967). Este dominio ideológico (poder) partió de uno de los miembros de la dicotomía, que fundamentado en el dispositivo de la biología y la sexualidad (Foucault, 1976), ha dado la hegemonía y representatividad al hombre, al padre -el que llega a ser persona pues tiene libertad (Bourdieu, 2000; Espósito, 2011)-, el dador de existencia: eje de todo lo creado.

Este entramado social se ha impuesto sobre los cuerpos y sobre las extensiones de este: las ciudades, los estados, los textos y discursos. Así, ha hecho que ese mundo simbólico se regenere a través de las instituciones existentes: primero, la familia como célula de toda vida en sociedad, luego, la escuela y, después, el resto de agrupaciones e instituciones como los medios de información.

Hoy, en la vida social, a las desigualdades se las reconoce como "violencia", pues usan la categorización para marginar y segregar. Cuando, se toma la denominación de género (Millán, 2011) nace la reacción académica contra el sistema androcéntrico en forma de una lucha política -Feminismo-, con la cual se busca deshacer el dominio masculino como cabeza de la especie más evolucionada. Se implanta el sintagma "violencia de género", donde se describe históricamente el papel de la mujer como una subordinada, sin derecho a autorrepresentarse, debido a que está naturalizado (Marqués, 1981; Bourdieu, 1988) su silencio, pues hay otro que habla, mira, escucha, dispone y piensa por ella (Fornet-Betancourt, 2009).

Dentro de este sistema, hombres y mujeres son encasillados tanto en un cuerpo como en un comportamiento (ethos) determinados. Se inscriben con el proyecto "virilidad", que es una idealización de las características masculinas de fuerte, reproductor, seductor, con aptitudes intelectuales, verbales, creativas, investigativas, de liderazgo y productivas. Su obligación son las profesiones de fuerza, económicas, de gobierno y genialidad -lo artístico se limita a algunas que se relacionen con lo intelectual-filosófico o científico-. Para ellos su educación ha de ser con este perfil. Su lugar está fuera del hogar-casa, de lo afectivo, emotivo y el cuidado del mismo o de sus hijos/ as. Asimismo, en esta configuración se filtran los deseos de una raza, clase social y poder hegemónico, es decir, todo 
lo aceptado dentro de la "masculinidad hegemónica" (Bourdieu, 2000).

A la mujer, por su parte, se le ha proyectado un cuerpo y ethos ha seguido unos parámetros, fundamentados desde la tradición romana y cimentados textualmente desde la llustración. Las dos figuraciones aceptadas han sido: el ángel del hogar y la mujer demonio o fatal, como se lo acuñó desde la Literatura en el Romanticismo y el Modernismo.

El primero está relacionado con la veneración mariana -igual que el culto a la dama del amor cortés (Bouch, et al., 2013)- (cristianismo, judaísmo), donde se ha recalcado el papel dependiente, sumiso, abnegado, de servicio, sacrificio y siempre en el espacio privado (Jiménez, 1999), donde su amor le ha obligado a servir a los maridos y a los hijos. Su realización única ha sido la maternidad, por ello, se le ha enseñado el amor romántico (Bosch, et al., 2013) y se le ha educado para este. A través de la literatura, la filosofía y la biología -en sí, todas las ciencias-, se ha abogado por este comportamiento (Lagarrigue, Sarmiento, Martí, Vaz Ferreira, etc., en Fornet-Betancourt, 2009). Dentro de esta representación está el tratarla como a una niña, sin mancha, fuente del amor ideal, sin derecho de ejercer su opinión, su voluntad, su decisión ni la participación sobre sí, su entorno, su cuerpo, su locación en la historia y en el futuro por existir a expensas del otro.
El segundo presenta a la figura femenina convirtiéndola en un objeto de deseo (muñeca), posesión y lujuria. Le ha dado características animales zorra, gata, perra, la cerebro de mono (autómata), vampiresa, gallina culeca, loba, vaca, desposeyéndola de su índole humana. Se la presenta como la tentadora del hombre, la culpable del pecado original, se la ha tachado de traicionera, puta, bruja, embaucadora, celestina, devora hombres, etc. (Dottien-Orsini, 1996).

Estas representaciones develan violencia tanto para hombres como para mujeres, pero con más desmedro para las últimas, que se traduce en altos índices de impacto sobre sus cuerpos y comportamientos, a lo que se reconoce como "violencia de género" y que, en la actualidad, afecta a la integridad de sus vidas, debido al incremento mundial de feminicidios.

Las acciones relevantes a iniciarse comienzan con una desnaturalización (Conde, 2009) del mundo simbólico o semiótico para denotar las falencias de este, ya que no es democrático seguir "una lógica dicotómica, jerárquica, lineal, excluyente y proyectiva que para entender el mundo necesita dividirlo hasta no poder volver a retomar y entender la relación de esas partes y menos su totalidad" (Bedregal, 2006). Asimismo, una revisión de los currículos oficiales y más los ocultos, donde se replican las biparticiones 
de los géneros que solo parten de la base biológica y que son, en sí, una construcción social, factible de enmendarse. La motivación para una reacción simultánea, tanto de hombres como de mujeres, para no replicar las "costumbres", "tradiciones"y "saberes", que tengan como fuente esta ideología, donde los diferentes, discapacitados o pobres no tienen derecho a la autorrepresentación y participación.

\section{CONCLUSIÓN}

En este estudio demostré que en la narrativa de las letras de las canciones se naturaliza la violencia de género. Esto ocurre porque este texto comunicativo recurre a una macroestructura básica para la cognición humana: el relato y a un momento sentimental determinado: la relación amorosa. Con esta técnica persuasivo-emotiva se interioriza el mensaje, que además es reiterado a través de otro canal, el visual, pues las canciones tienen su video promocional. Por ser un texto narrativo, se aplicó una lectura narratológica para reconocer en cuál de sus elementos se filtraba ese uso. Se comprobó que la violencia de género se utiliza en la focalización pues, a través de esta, se plasma el mundo simbólico, donde aparecen las perspectivas psicológicas, ideológicas, espacio-temporales y sociales, de ahí su importancia en mi interpretación y en la lectura crítica que se debe hacer a los productos sociales para la desnaturalización. Esta focalización, como lo he validado, emplea un lugar de la enunciación masculino, de ciudad y, generalmente, joven, donde se expresa su sociolecto. Allí, la representación de la mujer es creada de acuerdo con los arquetipos del mundo simbólico patriarcal: "mujer fatal" y "ángel". Ambas le quitan poder de participación, voz, autorrepresentación y derecho sobre su cuerpo, están creados en función de un sujeto logofalocéntrico.

Este empleo de la violencia de género no solo escoge como forma la canción de moda, sino otros como la publicidad, los cuentos de hadas, los cómics, las películas, las novelas ${ }^{1}$, los himnos, etc. En el campo mercantil, el cuerpo humano es cosificado y más el de la mujer, eso ocurre en los videos musicales, como lo he estudiado en una aplicación previa (1987-1998) Tampoco, son solo las canciones de este momento las cuales han

\footnotetext{
${ }^{1}$ El melodrama acentúa los papeles femeninos de ángel y demonio, incluso, se recurre a la relación con lo racial: rubia y morena. Igual empleo se dio con las novelas fundacionales del siglo XIX y las telenovelas como "Elif".
} 
servido para estos fines constructores de conductas y representaciones (ethos). Si recordamos un fragmento de un tango muy popular de hace unas décadas, decía:

Tomo y obligo. Tómese un trago.

De las mujeres mejor no hay que hablar.

Todas, amigo, dan muy mal pago y hoy mi experiencia lo puede afirmar. (...)

Fuerza canejo. Sufra y no llore

que un hombre macho no debe Ilorar.

(Romero, "Tomo y obligo", En Gardel, 1931)

Otros como "Mano a mano", "Sombra", "Esta noche me emborracho", o anteriores al corpus analizado, (20052006), "Camisa negra", "La Paga", "Mala gente", "Nada valgo sin tu amor", de Juanes, o "Mariposa traicionera" de Maná, o "Tres libras de cadera tu cadera,..." del General, o "Talento en TV" de Willie Colón, replican la misma focalización que he analizado, pues se basan en un mismo hipotexto, donde la mujer es agredida verbal y visualmente. Incluso, muchas letras explícitamente manifiestan el deseo de "pegarle", "matarle"2 o vengarse para ir "a su funeral". De igual modo, es- cuchamos canciones con focalización masculinizada en voces femeninas, donde se pondera la sumisión sin denotar las implicaciones de esa reiteración: "Tú", "La loba", de Shakira, o "Dos mujeres un camino" de Laura León, o "Hacer el amor con otro", de Alejandra Guzmán o, incluso, "Cuando un hombre te enamora" de Gloria Trevi y Alejandra Guzmán, etc. Es lo ocurrido con las canciones de la muestra presentada, donde ellas asumían y ponderaban ese rol, entonces, las jóvenes que escuchaban debían emular ese ethos, indirectamente eran educadas para ser así. Olvidan que la reflexión y el desarrollo del pensamiento son los grandes progresos humanos. Recuérdese que en esta manipulación de los sujetos, los hombres también son sometidos a un arquetipo que les limita y no les permite expresar sus deseos, porque solo así se logra la dominación de "la masculinidad hegemónica".

Es necesaria la desnaturalización -desconstrucción- del mundo simbólico del sistema patriarcal como discurso dominador. Esta lucha se da en estudios como este y por ello deben ser divulgados, pues luego del trabajo procurado por el feminismo, en todas sus vertientes, aún hay quienes defienden, replican y toman como verdadero para regir la

\footnotetext{
${ }^{2}$ Véase Martín Consuegra, María. "Vamos a analizar si estas canciones del pop español son machistas" en El país. 23 de febrero de 2017 <http://elpais.com/elpais/2017/02/20/icon/1487604596_200924.html > [Consulta: 10 junio de 2018] <http://elpais.com/elpais/2017/02/20/icon/1487604596_200924.html >
} 
vida, los presupuestos de ese paradigma obsoleto. Contra esos resquicios se debe embestir ${ }^{3}$. Así se lo ha hecho, por ello, he indagado en los rasgos de violencia psicológica, verbal, económica, discursiva, social, etc., pues una táctica para ejercer control, poder: mantener el stats quo, tanto en lo público como en lo privado, es denigrar a los otros, en este caso a la mujer. Ella es acallada, silenciada, ignorada, marginada, eliminada, reprimida, privada de su territorialidad, pensamiento, creencias, voz: autorrepresentación. Es tal el poder de esta verdad, que ha sido interiorizada por ellas mismas, la creen y la defienden (síndrome de indefensión aprendida, en Federación de Mujeres Progresistas).

Entonces, argumento por una crítica deconstructiva a los medios de información y sus productos, como las can- ciones de moda -tanto sus letras como sus videos-, donde se plasma mensajes que validan la violencia de género, pues, por lograr buen raiting, hacen uso de lo estereotipado y acentúan los presupuestos sociales de desigualdad, pues dejan a un lado el efecto (perlocution) causado en los espectadores, que siguen esa representación o ethos de lo que es ser hombre o mujer. Recordemos, que el público crea lo preferido en los medios de información y estos al primero en una constante réplica, cuyo logro es mantener una cultura, ideología manifestándose así su poder. Frases dichas al aire dentro de la conversación, reiteran la discriminación aprendida y la perspectiva -focalización- androcéntrica, incluso, la repiten los niños y niñas sin ninguna intención: "Manejas como una mujer", "Soy una loba en celo", "Esa es una bruja", etc.

\footnotetext{
${ }^{3}$ Por ejemplo, en estos blog y páginas hay una propuesta sobre el tema. Aconsejo visitarlas: <http://imaginacionesfilmicas.com/>; < http://www.garuyo.com/musica/canciones-contra-la-mujer-misoginas-machistas-en-espanol> [Consultado: 10 de junio de 2018]
} 


\section{BIBLIOGRAFÎA}

Austin, J. (1962). Cómo hacer cosas con las palabras. Barcelona: Paidós.

Bhabha, H. (2013). El lugar de la cultura. Buenos Aires: Manantial.

Bajtin, M. (1986). Problemas de la Poética de Dostoievski. Bogotá: Fondo de Cultura Económica.

Bordieu, P. (1988). La distinción. Criterios y bases sociales del gusto. Madrid: Taurus.

(2000). La dominación masculina. Barcelona: Anagrama.

Butler, J. (2002). Cuerpos que importan: sobre los límites materiales y discursivos del "sexo". 1.0 ed. Buenos Aires: Paidós.

Bedregal, X. "Con mi feminismo mirando al Sur". Ponencia leída en el V Encuentro Feminista Boliviano, abril del 2006 [en línea]. Recuperado de: <ximena@creatividadfeminista.org $>$ [Consulta: 3 junio 2018].

Bosch, E., et al. (2013). Violencia contra las mujeres: el amor como coartada. Barcelona: Anthropos.

Calsamiglia, H. y Tusón, A. (2001). Las cosas del decir. Barcelona: Ariel.

Colaizzi, G. (1990). Feminismo y Teoría del discurso. Madrid: Cátedra,

Conde, F. (2009). Análisis sociológico del sistema de discursos. Colección cuadernos metodológicos, n. 43.
Madrid: CIS.

Corrales Pascual, M. (2000). Iniciación a la narratología. Quito: Centro de Publicaciónes.

Cortés Rodríguez, L. y Camacho, (2003). ¿Qué es el Análisis del Discurso? Barcelona: Octaedro.

Da Silva, T. (2004). Documentos de Identidade. Belo Horizonte: Autêntica Editora.

Derrida, J. (1967). De la grammatologie. Paris: Les éditions de Minuit.

Dottín-Orsini, M. (1996). La Mujer Fatal (según ellos). Argentina: De la Flor S. R. L.

Elefantes, "Mentirosa". En Elefante, S. productor, Sony Music, 2005, [CD], Pista 3.

Esposito, Roberto (2011). El dispositivo de la persona. Buenos Aires: Amorrortu.

Evans, Mary (1997). Introducción al Pensamiento Feminista Contemporáneo. Madrid: Minerva Ediciones.

Federación de Mujeres Progresistas. "Lenguaje sexista y violencia en medios de comunicación", Violencia de Género. [En línea]. Recuperado de: <http://www.fmujeresprogresistas.org/violencia. htm > [Consulta: 20 febrero 2018].

Fornet-Betancourt, R. (2009). Mujer y filosofía en el pensamiento ibe- 
roamericano. Barcelona: Anthropos.

Foucault, M. (1976). Histore de la Sexualité. Vol. 1. Paris: Gallimard. (1990). Vigilar y Castigar. México: Siglo XXI. (2005). Arqueología del Saber. Argentina: Siglos XXI Editores.

(2000). Los anormales.

México: Fondo de Cultura Económica.

Jiménez, Onilda A. (1999). La mujer en Martí. Miami: Universal.

Maingueneau, D. en Alvarado, Ramón (1996). El ethos y la voz de lo escrito. Revista Versión 6. México: 79-92. [en línea]. Recuperado de: $<$ http://bidi.xoc.uam.mx/resumen_articulo.php?id=2004\&archivo=7-135-2004rqb.pdf\&titulo_articulo=El\%20ethos $\% 20$ y \% 20la \% 20voz \% 20 de \% 20 lo\%20escrito\%20(traducci\%F3n\%20de\%20Ram\%F3n\%20 Alvarado) $>$ [Consulta: 27 octubre de 2017].

Maná, "Bendita tu luz". En Amar es combatir, Warner Music, Fher Olvera, 2006, [CD], Pista 7.

Maná, "Labios compartidos". En Amar es combatir, Warner Music, Fher Olvera, 2006, [CD], Pista 2.

Martin, Ricky, "Tu recuerdo". En MTV Unplugged, Tommy Torres, Co- lumbia, Florida, 2006, [CD], Pista 3. Marqués, J. V. (1981). No es natural. Para una sociología de la vida cotidiana. Barcelona: Anagrama.

Medina Carballo, M. (2004). "Reflexiones sobre el discurso desde una perspectiva integradora". Perspectivas docentes. No. 28. Acotaciones. Revista de la Universidad de Juárez. Tabasco-México.

Millan, M. (2011). "De la 'economía política del sexo' al 'género': Ios retos heurísticos del feminismo contemporáneo". En Revista Mexicana de Discurso, teoría y análisis (31). México: Universidad Nacional Autónoma de México, IIS. 7593.

Miño, Fausto, "Baila mi vida". En Yo soy, Universal Music Group, Alfredo Vera, 2007, [CD], Pista 8.

Moreira, A. y Da Silva, orgs (1994). Currículo, Cultura e Sociedade. São Paulo: Cortez.

Moreno Llaneza, M. (octubre, 2004). "Las autoridades educativas advierten que no coeducar perjudica seriamente la salud", Curso ¿Dónde Están Las Niñas? La Perspectiva De Género En La Educación Para La Salud Y El Deporte [en línea]. Recuperado de: $<$ http://www.educastur.princast.es/cpr/aviles/ asesorias/sociolin/coeducación. htm> [Consulta: 27 mayo 2007]. 
Pearson, J. et al. (1993). Comunicación y

Género. Barcelona: Paidós.

RBD, "Ser y parecer". En Celestial. EMI Muscic México S.A, Televisa, Carlos Lara y Armando Ávila, 2006, [CD], Pista 2.

Reik, "Noviembre sin ti". En Reik. Sin productor. SM Entertainment México, [CD], 2005, Pista 7.

Reyes, G. (1994). Pragmática Lingüística. Barcelona: Montesinos.

Ricœur, P. (2001). Teoría de la interpretación literaria. México: Siglo XXI.

Rivera, Chris, "Maldita bruja". En A mi dios. Sencillo. S. disquera, 2007, [CD].

Romero, Manuel, "Tomo y obligo". En Carlos Gardel, Odeon, Ifesa, 1931, [LP-12-19060]. Pista 7.

(1995). Alienígenas na

Sala de Aula. Petrópolis, RJ: Vozes.

Sullà, E., ed. (1996). Teoría de la novela.

Barcelona: Crítica.

Tannen, D. (1996). Género y Discurso. Barcelona: Paidós.

Torres, Santomé, Jurjo, "As Culturas Negadas e Silenciadas no Currículo".
En Tomaz Tadeo Da Silva (2003). Alienígenas na Aula de Clase. Petrópolis: Editora Vozes,

Van Dijk, T. (1980). Estructuras y funciones del discurso. México: Siglo XXI. (2000). El Discurso como estructura y proceso. Barcelona: Gedisa.

Velasco, Juan Fernando y Mejía, Gerardo, "Frente a Frente". En Tanto amor. Cover, Unión Music Group, FM Entretenimiento, 2007, [CD], Pista 8.

Venegas, Julieta, "Limón y sal". En Limón y sal, Cachorro López y Julieta Venegas, Sony Music, 2006, [CD], Pista 4.

Viñas Pinquer, D. (2002). Historia de la Teoría Crítica Literaria. Barcelona: Ariel.

Wodak, R. y Michael Meyer, eds. (2002) Métodos de análisis crítico del discurso. Barcelona: Gedisa. 